Андрей Корбут

\title{
АТИПИЧНОЕ ВЗАИМОДЕЙСТВИЕ И КОНВЕРСАЦИОННЫЙ АНАЛИЗ
}

\section{Wilkinson R., Rae J.P., Rasmussen G. (eds.) (2020) Atypical Interaction: The Impact of Communicative Impairments within Everyday Talk. Cham: Palgrave Macmillan, 470 p. ISBN: 978-3- 030-28798-6}

\section{DOI: $10.17323 / 727-0634-2021-19-4-737-743$}

Особенности взаимодействия с людьми, коммуникативные способности которых нарушены в результате заболевания или травмы, начали интересовать исследователей коммуникации с середины XX в. Благодаря появлению необходимых теоретических (например, кибернетики) и методологических (данных систематических наблюдений) ресурсов социальные ученые пересмотрели устоявшееся представление о коммуникативных расстройствах как исключительно психологических нарушениях. Одним из первых, кто начал анализировать социальные механизмы коммуникативных расстройств, был Грегори Бейтсон, который вместе с рядом коллег в 1950-е гг. сформулировал коммуникативную теорию шизофрении (Bateson et al. 1956). Позже, по мере появления новых подходов в социальных науках, прежде всего в социолингвистике, изучение коммуникативных расстройств стало частью многих исследовательских традиций, например в теории речевых актов (Price-Williams, Sabsay 1979; Abbeduto, Rosenberg 1980). Однако эти исследования часто носили спекулятивный характер и не обладали необходимой эмпирической строгостью.

Подходящие методологические и концептуальные инструменты для изучения того, что получило название «атипичного взаимодействия», предложены в рамках традиции конверсационного анализа, сложившейся в начале 1970-х гг. Родоначальники этого подхода и их коллеги сформулировали базовые принципы детального эмпирического анализа социальных взаимодействий (Sacks et al. 1974), которые затем были применены и к атипичной коммуникации. Сегодня существует значительное число исследований атипичного взаимодействия, выполненных в традиции конверсационнного анализа (напр., Yearley, Brewer 1989; Perkins 1995; Oelschlaeger, Damico 1998; Wootton 1999; Heeschen, Schegloff 1999; Goodwin 2000, 2003; Skelt 2010; Auer, Bauer 2011; Egbert, Deppermann 2012; Wilkinson 2013, 2014; Wilkinson et al., 2011). Поэтому можно утверждать, что это сложившееся научное направление. Однако до сих пор не выходило сборников, в которых были бы собраны работы, посвященные исключительно конверсационному

Андрей Михайлович Корбут- к.соц.н., ст.н.с., Центр фундаментальной социологии, Национальный исследовательский университет «Высшая школа экономики», Москва, Россия. Электронная почта: akorbut@hse.ru 
анализу атипичного взаимодействия. Рецензируемая книга, которая является первым таким коллективным трудом, представляет собой важный этап в развитии данной области исследований.

В сборнике «Атипичное взаимодействие: влияние коммуникативных расстройств в повседневном общении», вышедшем в 2020 г. под редакцией Рэя Уилкинсона, Джона Рэя и Гитте Расмуссен, собраны работы ведущих исследователей, занимающихся конверсационным анализом атипичного взаимодействия. Атипичное взаимодействие понимается в книге как «естественно протекающий разговор или другие формы социального взаимодействия, при которых хотя бы у одного из участников имеется коммуникативное нарушение, влияющее на взаимодействие» (РP. 1-2). Это первая такого рода коллективная публикация, которая не только свидетельствует о существовании обширной сети представителей разных дисциплин, применяющих конверсационный анализ для изучения взаимодействия людей с коммуникативными расстройствами, но и позволяет оценить исследовательские возможности, открываемые этим подходом.

Поскольку все работы в сборнике основываются на конверсационном анализе, в них изучаются аудио- и видеозаписи взаимодействий людей с теми или иными нарушениями: аутизмом (гл. 2 и 3), умственной отсталостью (гл. 4), шизофренией (гл. 5), деменцией (гл. 6 и 7), афазией (гл. 8, 9 и 13), речевыми, языковыми и коммуникативными особенностями (гл. 10), заиканием (гл. 11), дизартрией (гл. 12 и 13), нарушениями слуха (гл. 14 и 15). Акцент на изучении естественных повседневных взаимодействий при этом принципиально важен. В статьях сборника мы видим не то, как люди с коммуникативными расстройствами справляются со специальными тестами и заданиями, а как они ведут себя в привычной бытовой и институциальной обстановке, в которой общаются с родственниками, врачами, учителями, случайными незнакомцами, полицией и т. д. Соответственно, сбор данных для исследований, представленных в сборнике, предполагал минимальное вмешательство исследователей: чаще всего это были видеозаписи обычных ситуаций без какого-либо предварительного задания. В некоторых случаях исследуемые сами делали записи своих повседневных ситуаций по просьбе исследователей (гл. 8 и 12) или исследователи брали записи, выложенные в открытый доступ (гл. 2 и 11).

Сборник включает 15 статей и состоит из четырех частей, объединяющих тексты в зависимости от типа изучаемых в них расстройств: в первой части рассматриваются когнитивные расстройства, во второй-расстройства языка, в третьей- расстройства беглости речи, в четвертой-речевые расстройства и расстройства слуха. Это деление, разумеется, условно, поскольку многие болезни вызывают расстройство разных функций. Что объединяет все рассматриваемые случаи-это то, что они свидетельствуют о нарушении повседневных коммуникативных практик людей, страдающих теми или иными расстройствами. Это оправдывает применение к ним 
подхода, который как раз нацелен на изучение повседневных ситуаций взаимодействия - конверсационного анализа (КА).

КА важен для изучения атипичного взаимодействия по двум причинам. Во-первых, в КА накоплено множество данных, касающихся типичного взаимодействия. Работы, представленные в сборнике, опираются на этот массив данных и используют как полученные ранее результаты, так и понятия, разработанные в КА. В некоторых случаях при изучении атипичного взаимодействия методология КА требует некоторой доработки (например, когда используется жестовый язык, как в ситуациях, рассматриваемых в гл. 15), но это не меняет принципиально базовые принципы подобных исследований. Конечно, в КА накоплены и данные, касающиеся атипичного взаимодействия, но соответствующие систематические исследования начались относительно недавно, в середине 1990-х гг. (см.: Wilkinson 2019).

Во-вторых, применение КА к атипичному взаимодействию оправдано тем, что одним из ключевых феноменов любых форм взаимодействия является то, что в КА получило название repair, т.е. «исправление», «поправка» или «починка». Это повсеместно встречающийся интеракционный феномен, который особенно важен в случае изучения взаимодействия людей с коммуникативными расстройствами, поскольку их коммуникативные практики отличаются от привычных и, тем самым, гораздо чаще вызывают потребность как у них самих, так и у их собеседников «чинить» проблемы понимания, говорения или слушания. Большинство авторов сборника рассматривают различные стратегии исправления, применяемые в атипичном взаимодействии. Это позволяет, среди прочего, выявить специфику атипичного взаимодействия по сравнению с «типичным»: если в типичном взаимодействии наблюдается предпочтение «самоинциированного самоисправления», когда говорящий указывает на проблему и исправляет ee (Schegloff et al. 1977), то «данные исследований асимметричных взаимодействий говорят о том, что в них организация починки может... не склоняться к самокоррекции... но из-за лингвистических сложностей высказывания менее компетентных говорящих могут завершаться или даже корректироваться другими» (Р. 282). Иными словами, в атипичном взаимодействии обнаруживается предпочтение «самоинициированного исправления другим» или «инициированного другим самоисправления».

Благодаря применению этого подхода собранные в сборнике исследования демонстрируют возможность интеракционного переопределения болезни. Обычно коммуникативные расстройства рассматриваются в качестве проявлений той или иной болезни. Детальный анализ реальной коммуникации людей с этими расстройствами показывает, что болезнь сама может быть рассмотрена в качестве формы коммуникации. Такое переопределение включает три компонента.

1. Как показывают многие статьи в сборнике, люди с коммуникативными нарушениями более интеракционно компетентны, чем кажется 
и чем принято считать. Например в главе «Пение как ресурс в разговорах в участием людей с деменцией» Гитте Расмуссен показывает, что спонтанные и неожиданные эпизоды пения людей, страдающих деменцией, являются не только следствием определенных когнитивных нарушений (согласно данным медицинских исследований, в случае деменции способность воспринимать и воспроизводить музыку остается сохранной дольше, чем способность воспринимать и воспроизводить речь), но и отражают довольно высокую коммуникативную компетенцию больных деменцией. Они выбирают момент для пения и содержание пения исходя из текущей коммуникативной ситуации, что требует довольно тщательного мониторинга хода разговора. Для человека, который не привык к тому, что их собеседник начинает внезапно петь, такое пение кажется неуместным. Но внимательное рассмотрение подобных ситуаций обнаруживает тонкую интеракционную работу, которую выполняют больные деменцией, когда неожиданно начинают петь. Аналогичная «скрытая компетентность» обнаруживается при изучении языковых практик больных шизофренией. В главе «Предполагает ли атипичность расстройство?» Лиза Майкселл показывает, что аномально частое использование в речи человеком с шизофренией связки «как я и говорил» при более детальном анализе оказывается специфическим способом поддержания последовательности взаимодействия, а не ее разрушения.

2. В большинстве статей из сборника демонстрируется, что интеракционная компетентность людей с коммуникативными нарушениями- это совместное, коллективное достижение, а не индивидуальное качество. Если изучать не отдельно взятого человека в искусственной лабораторной ситуации (как делают, например, врачи и психологи, проводящие диагностические тесты), а человека в естественных, обыденных ситуациях жизни, то обнаруживается, что способность людей с нарушениями вести эффективную коммуникацию основывается на совместных усилиях, которые предпринимают они и их собеседники. Например, в главе «Создание и использование возможностей для совместного участия во взаимодействии между мальчиком с расстройством аутистического спектра и его отцом» Джон Рэй и Моника Рэми показывают, что в процессе игры с мальчиком, больным расстройством аутистического спектра, отец использует элементы обстановки и ход разговора для создания ситуаций, в которых мальчик может демонстрировать свою коммуникативную компетентность (к примеру, отец может помещать действия мальчика, не соответствующие ситуации, в специальные «интеракционные кавычки» с помощью шутки). Авторы называют это scaffolding (Р. 67), т. е. буквально «возведением подмостков» или «поддержкой».

Совместная интеракционная работа человека с нарушениями и их собеседников также демонстрируется в главе «Меняющаяся детализация», в которой Скотт Барнс и Франческо Поссемато описывают механизмы коллективного выстраивания чередов людьми с афазией и их партнерами 
по взаимодействию. Партнеры могут, например, добавлять к буквам и слогам, произносимым людьми с афазией, но не получающим продолжение, буквы и слоги, которые «подсказывают», что нужно произносить дальше. Подобные стратегии интеракционной поддержки позволяют сохранять за людьми с коммуникативными нарушениями «автономию говорящего» (Р. 374), даже несмотря на то, что они демонстрируют очевидную неспособность вести разговор «типичными» способами. Один из наиболее распространенных приемов обеспечения такой автономии-предоставление людям с нарушениями возможности и права оценивать адекватность оказанной коммуникативной «помощи» (например, они могут после предложенного за них слова вербально и невербально оценивать адекватность этой «догадки»). Однако такая совместная природа коммуникативной компетентности, которая становится особенно очевидна в случае атипичной коммуникации, несет с собой определенные риски (см. гл. 11).

3. Наконец, еще один аспект интеракционного переопределения болезни, предпринимаемого в сборнике, заключается в том, что, как показывают публикуемые в нем исследования, многие люди с коммуникативными расстройствами и их собеседники сталкиваются с дилеммой «прогрессивность vs интерсубъективность» (Р. 512). Речь идет о решении, что поставить на первое место: продвижение разговора или достижение взаимопонимания. Если человек с коммуникативным расстройством сталкивается с проблемой (скажем, не может произнести определенное слово или слышит, что собеседник неправильно «угадал», что он/она сказал), он/она может потратить определенное время (иногда довольно продолжительное) на решение этой проблемы, но тогда взаимодействие будет «поставлено на паузу» и собеседники не перейдут к новой теме. Эта дилемма часто решается в пользу прогрессивности, т. е. участники игнорируют возникающие сложности ради продвижения разговора, но в некоторых случаях выбор делается, наоборот, в пользу интесубъективности. Последний вариант наблюдается, например, когда собеседники хотят «научить» человека с коммуникативными нарушениями вспоминать или правильно произносить определенные слова (см. гл. 10).

Говоря об интеракционном переопределении болезни, следует помнить, что лишь небольшая часть заболеваний приводит к коммуникативным расстройствам и не все формы атипичного взаимодействия определяются тем или иным заболеванием. Но при изучении взаимодействий людей с коммуникативными нарушениями три выделенных аспекта такого переопределения позволяют взглянуть на атипичную коммуникацию в перспективе, которая зачастую упускается в других подходах: с точки зрения совместных, коллективных, а не индивидуальных практик. Это позволяет рассматривать коммуникативные расстройства как что-то более подвижное и процессуальное, чем в случае «медицинских» или «психологических» подходов, что, в свою очередь, может быть важным элементом демедикализации подобных нарушений. 
Одной из важных характеристик представленных в сборнике исследований, концентрирующихся на атипичных коммуникативных практиках, является возможность использования результатов этих исследований в рамках программ реабилитации, обучения или лечения. С одной стороны, детальный анализ реальных коммуникативных практик позволяет понять, с какими трудностями во взаимодействии сталкиваются люди с коммуникативными нарушениями, что позволяет более точно выстраивать лечебные и реабилитационные процедуры- Уилкинсон называет это «интеракционно-сфокусированным вмешательством» (Р. 27). При этом изучение динамики коммуникативных практик позволяет оценивать эффективность тех или иных форм вмешательства. С другой стороны, результаты этих исследований могут использоваться для обучения как специалистов, так и родственников людей с коммуникативными расстройствами наиболее эффективным способам взаимодействия с ними.

Andrei Korbut

\section{ATYPICAL INTERACTION AND CONVERSATION ANALYSIS \\ Wilkinson R., Rae J. P., Rasmussen G. (eds.) (2020) Atypical Interaction: The Impact of Communicative Impairments within Everyday Talk. Cham: Palgrave Macmillan, 470 p. ISBN: 978-3- 030-28798-6}

DOI: $10.17323 / 727-0634-2021-19-4-737-743$

\section{References}

Abbeduto L., Rosenberg S. (1980) The Communicative Competence of Mildly Retarded Adults. Applied Psycholinguistics, 1 (4): 405-426.

Auer P., Bauer A. (2011) Multimodality in Aphasic Conversation: Why Gestures Sometimes Do Not Help. Journal of Interactional Research in Communication Disorders, 2 (2): 215-243.

Bateson G., Jackson D. D., Haley J., Weakland J. (1956) Toward a Theory of Schizophrenia. Behavioral Science, 1 (4):251-264.

Egbert M., Deppermann A. (eds.) (2012) Hearing Aids Communication: Integrating Social Interaction, Audiology and User Centered Design to Improve Communication with Hearing Loss and Hearing Technologies. Mannheim: Verlag für Gesprächsforschung.

Andrei Korbut-Cand. Sci. (Sociol.), Senior Research Fellow, Centre for Fundamental Sociology, HSE University, Moscow, Russian Federation. Email: akorbut@hse.ru 
Goodwin C. (2000) Gesture, Aphasia and Interaction. In: D. McNeill (ed.) Language and Gesture. Cambridge: Cambridge University Press: 84-98.

Goodwin C. (ed.) (2003) Conversation and Brain Damage. New York: Oxford University Press.

Heeschen C., Schegloff E. A. (1999) Agrammatism, Adaptation Theory, Conversation Analysis: On the Role of So-called Telegraphic Style in Talk-in-Interaction. Aphasiology, 13(4/5):365-406.

Perkins L. (1995) Applying Conversational Analysis to Aphasia: Clinical Implications and Analytic Issues. European Journal of Disorders of Communication, 30 (3):372-383.

Price-Williams D., Sabsay S. (1979) Communicative Competence among Severely Retarded Persons. Semiotica, 26 (1-2): 35-64.

Sacks H., Schegloff E. A., Jefferson G. (1974) A Simplest Systematics for the Organization of Turn-Taking for Conversation. Language, 50 (4): 696-735.

Schegloff E.A., Jefferson G., Sacks H. (1977) The Preference for Self-Correction in the Organization of Repair in Conversation. Language, (2):361-382.

Skelt L. (2010) "Are you looking at me?”: The Influence of Gaze on Frequent Conversation Partners' Management of Interaction with Adults with Acquired Hearing Impairment. Seminars in Hearing, 31 (2): 116-216.

Wilkinson R. (2013) Conversation Analytic Investigations of Dysarthria and Hearing Impairment: The Impact of Motor and Sensory Impairments in Social Interaction. Journal of Interactional Research in Communication Disorders, 4 (1): 1-26.

Wilkinson R. (2014) Intervening with Conversation Analysis in Speech and Language Therapy: Improving Aphasic Conversation. Research on Language and Social Interaction, 47 (3):219-238.

Wilkinson R. (2019) Atypical Interaction: Conversation Analysis and Communicative Impairments. Research on Language and Social Interaction, 52 (3):281-299.

Wilkinson R., Bloch S., Clarke M. (2011) On the Use of Graphic Resources in Interaction by People with Communication Disorders. In: J. Streeck, C. Goodwin, C. LeBaron (eds.) Embodied Interaction: Language and Body in the Material World. Cambridge: Cambridge University Press: $152-168$.

Wootton A. J. (1999) An Investigation of Delayed Echoing in a Child with Autism. First Language, 19 (57):359-381.

Yearley S., Brewer J. D. (1989) Stigma and Conversational Competence: A Conversation Analytic Study of the Mentally Handicapped. Human Studies, (12):97-117.

Oelschlaeger M.L., Damico J. S. (1998) Joint Productions as a Conversational Strategy in Aphasia. Clinical Linguistics \& Phonetics, 12 (6): 459-480. 